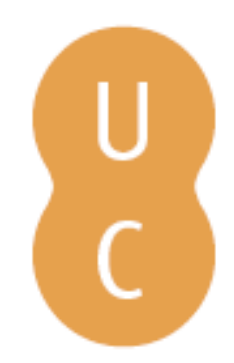

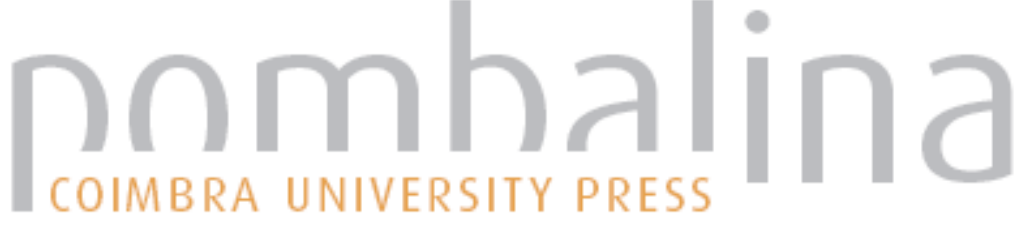

\section{Património e turismo literário: Leiria Queiroziana}

\author{
Autor(es): $\quad$ Fernandes, Sara; Carvalho, Paulo
}

Publicado por: Imprensa da Universidade de Coimbra

URL

persistente: URI:http://hdl.handle.net/10316.2/43527

DOI: $\quad$ DOI:https://doi.org/10.14195/978-989-26-1343-7_31

Accessed : $\quad$ 26-Apr-2023 13:56:14

A navegação consulta e descarregamento dos títulos inseridos nas Bibliotecas Digitais UC Digitalis, UC Pombalina e UC Impactum, pressupõem a aceitação plena e sem reservas dos Termos e Condições de Uso destas Bibliotecas Digitais, disponíveis em https://digitalis.uc.pt/pt-pt/termos.

Conforme exposto nos referidos Termos e Condições de Uso, o descarregamento de títulos de acesso restrito requer uma licença válida de autorização devendo o utilizador aceder ao(s) documento(s) a partir de um endereço de IP da instituição detentora da supramencionada licença.

Ao utilizador é apenas permitido o descarregamento para uso pessoal, pelo que o emprego do(s) título(s) descarregado(s) para outro fim, designadamente comercial, carece de autorização do respetivo autor ou editor da obra.

Na medida em que todas as obras da UC Digitalis se encontram protegidas pelo Código do Direito de Autor e Direitos Conexos e demais legislação aplicável, toda a cópia, parcial ou total, deste documento, nos casos em que é legalmente admitida, deverá conter ou fazer-se acompanhar por este aviso.

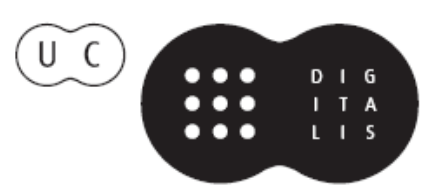




\section{FERNANDA CRAVIDÃO}

\section{IÚCIO CUNHA}

PAULA SANTANA

\section{NORBERTOSANTOS}

(ORG.)

\section{ESPAÇOS E TEMPOS EM GEOGRAFIA}

HOMENAGEM A ANTÓNIO GAMA

IMPRENISA DÁ UNIVERSIDADE DE COIMBRA COIMBRA UNIVERSITY PRESS

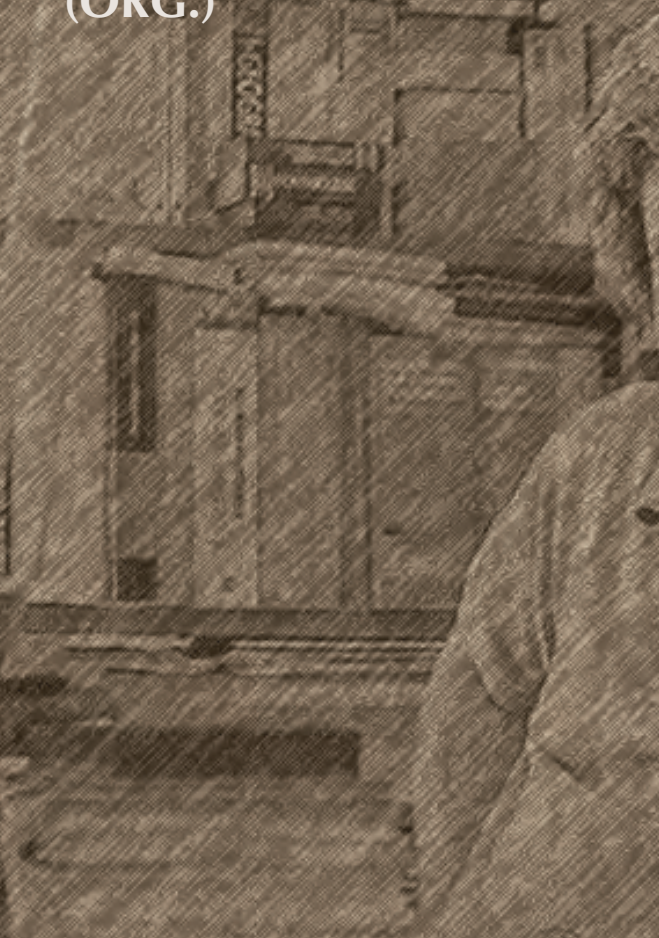




\section{PATRIMÓNIO E TURISMO LITERÁRIO: LEIRIA QUEIROZIANA}

\section{Sara Fernandes/sarapcfernandes@gmail.com}

Mestre em Lazer, Património e Desenvolvimento Universidade de Coimbra

\section{Paulo Carvalho/paulo.carvalho@fl.uc.pt}

Departamento de Geografia e Turismo da Faculdade de Letras da Universidade de Coimbra e CEGOT - Centro de Estudos de Geografia e Ordenamento do Território

\section{Património e turismo literário}

\section{Património, sítio e itinerário literário}

A palavra literatura surge nos finais do século xv, do latim "littera" que significa "letra", associando-se à arte de escrever e à letra escrita ou impressa. Mais tarde, atribuiu-se importância à relação entre o autor, a obra e o recetor, sendo que a partir da década de 1960, considera-se que o principal objetivo da literatura seria a criação de um processo de comunicação entre autor e leitor (Carvalho, 2009).

Desta forma, através da literatura o autor transmite uma mensagem e um legado emocional e espacial ao leitor, ao longo das geraçóes, o que conduz ao conceito de "património literário". O património literário assume especial 
importância, na medida em que a literatura é um meio de perpetuar e (re) construir a memória individual (do autor ou do escritor) e coletiva (da sociedade), valorizando a herança cultural de uma determinada sociedade. No entanto, esta memória material e imaterial do lugar é condicionada pela visão e perspetiva do seu autor em determinado momento, o que constitui um elemento valorizador para os espaços, na medida em que se associa um autor ou obra a um determinado local, dinamizando-o (Henriques e Quinteiro, 2011).

$\mathrm{Na}$ tentativa da promoção dos lugares surgem dois conceitos diferenciados: sítio literário e itinerário literário. O sítio literário diz respeito ao lugar ao qual é associado um autor, quer seja pela sua vida ou ficção (obra literária) e que, nesse sentido, mistura passado e presente. Por outro lado, o itinerário literário procura estabelecer uma relação "entre diversos locais, paisagens ou atracçóes associadas a um escritor ou poeta" (Carvalho, 2009: 24), que pode envolver diferentes localidades, num sistema em rede.

Os itinerários literários "Podem ser seguidos por turistas de forma independente ou pode haver organização no destino de modo a promover a sua associação com o escritor e a potenciar a experiência do visitante" (Carvalho, 2009: 24) e "exaltam o sortilégio de promoverem uma autêntica fusão de horizontes entre a cultura do turista e a cultura do "anfitrião" na medida em que radicam de forma existencial valores estéticos que são, intrinsecamente, éticos" (Mendes, 2007: 84).

Neste sentido, os lugares capazes de provar a sua ligação autêntica a um determinado autor ou obra possuem um vantajoso recurso turístico, capaz de movimentar turistas - o património literário.

\section{A turistificação da literatura}

Nos últimos anos, face às crescentes alteraçôes do mercado turístico e exigências dos consumidores, o turismo mundial tem procurado, através dos nichos de mercado, responder a essas necessidades e expectativas. 
Desde cedo que turismo e cultura se interligaram, porém, apenas a partir da segunda metade do século xx, o turismo cultural se configurou como uma alternativa ao turismo massificado europeu, que se estende a todos os domínios, pois diz respeito às manifestaçóes e costumes de um povo. Nessa perspetiva, pode-se dizer que o turismo literário é um nicho de mercado do turismo cultural, porque procura diferenciar o produto turístico e preservar a cultura local.

De facto, segundo Hopen et al. (2014), o turismo literário pode ser considerado um nicho turístico relacionado com os media (onde se insere também o turismo cinematográfico), dentro do nicho turístico criativo ${ }^{1}$, dentro do largo campo do turismo cultural e patrimonial (Figura 1).

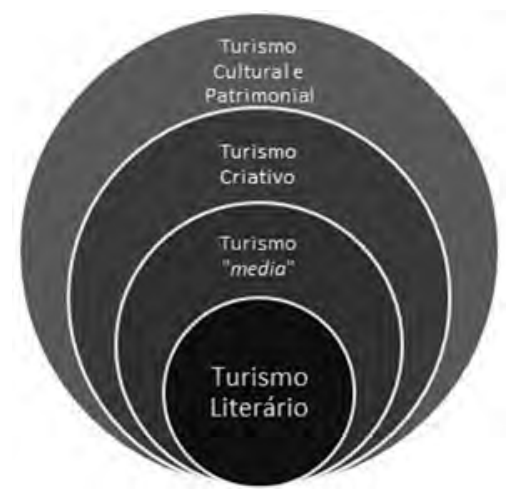

Figura 1

Classificação do Turismo Literário

Fonte: Adaptado de Hopen et al. (2014:40).

Mendes (2007: 87), advoga que o turismo literário "privilegia os lugares e os eventos dos textos ficcionados, bem como a vida dos seus autores, promovendo a ligação entre a produção literária e artística de um autor e os turistas

\footnotetext{
${ }^{1}$ Importa sublinhar que o turismo criativo inclui a participação ativa dos visitantes, com o desenvolvimento de dimensôes pedagógicas, sociais e emocionais (Richards, 2011). "Nesta vivência e partilha de experiências, a procura da autenticidade e da cultura social surgem como elementos paulatinamente mais valorizados, uma vez que proporcionam uma aproximação mais fidedigna ao quotidiano dos territórios e às populaçōes que neles vivem” (Maurício, 2013: 6).
} 
que visitam esses locais". Favorece as "relaçóes com o texto - ou seja, as pontes estabelecidas enquanto leitor da obra e conhecedor da vida do autor - e as relaçóes para além do texto, isto é, as memórias suscitadas e as experiências despoletadas pelos mesmos factores" (Maurício, 2013: 6).

Anterior ao turista literário, existia a ideia de “peregrino literário", erudito preparado para viajar longas distâncias até locais relacionados com escritores. Estes peregrinos seriam turistas escolarizados nas disciplinas clássicas e com um capital cultural que lhes permitia apreciar este património. Contudo, com a democratização e crescimento do turismo cultural, os sítios literários ocupam um lugar privilegiado nas preferências dos turistas, não só pela sua importância cultural, como aconteceria com os peregrinos, como também devido a uma "conveniência geográfica”, que os posiciona nos principais circuitos turísticos culturais (Herbert, 2001; Carvalho, 2009).

De acordo com Herbert (2001), as principais razóes que levam um turista a visitar um sítio literário são quatro. A primeira diz respeito a lugares relacionados com a vida dos escritores (como a casa-museu Miguel Torga, em Coimbra), a segunda diz respeito aos sítios que serviram de cenário a uma obra (como Sintra, em Os Maias, de Eça de Queirós), a terceira diz respeito aos sítios que se relacionam com o autor ou a obra e despertam no turista memórias ou emoçóes (da sua infância, por exemplo) e a quarta diz respeito aos sítios que se relacionam com um evento dramático da vida do autor (como o local da sua morte).

A construção de sítios literários não ocorre de forma espontânea. Estes são o resultado da junção de qualidades excecionais dos locais (relacionadas com o património literário) e de qualidade gerais (relacionadas com a localização, capacidade atrativa, serviços e facilities turísticos), mediados por políticas de ação que conduzirão ao sucesso turístico do lugar (Herbert, 2001).

As políticas de construção do sítio literário são controladas pelos produtores locais e descodificadas e interpretadas de várias formas pelos visitantes. Deste modo, pode-se dizer que os sítios literários são socialmente construídos, através de uma permanente interação entre promotor e consumidor, que levanta o problema da autenticidade do lugar. Contudo, no turismo literário a autenticidade 
é indissociável da interpretação individual e, nesse sentido, ao turista literário importa, em primeiro lugar, conhecer o mais perto da realidade ou um "simulacro do autêntico", desde que relacionado com a vida e obra do autor (Sardo, 2009: 343), isto é, uma fusão entre o real e o imaginário - paisagens turístico-literárias.

Em suma, à semelhança do turista cultural, o turista literário interessa-se pela "forma como os lugares influenciaram a escrita e, ao mesmo tempo, como a escrita criou determinados lugares" (Sardo, 2009: 341) e, por isso, diz respeito aos leitores que se interessam pelos pormenores, habitualmente mais escolarizado e com um maior rendimento disponível, cujo segmento etário se situa entre os 35 e os 54 anos. Assim, é um turista mais exigente, com algum conhecimento prévio à deslocação e que procura, com as suas viagens, aprender e experienciar outras culturas.

\section{Importância do património literário para o desenvolvimento local}

Atualmente, a ligação entre turismo e cultura é um dos objetivos e prioridades para o futuro. De acordo com o Plano Estratégico Nacional de Turismo, a construção da marca "Destino Portugal" deve assentar, entre outras coisas, na promoção da "História, Cultura e Tradição" do país e um dos produtos estratégicos - os Circuitos Turísticos - destaca a diversidade do património cultural português (MEE: 2013).

Neste sentido, urge apostar em novos produtos turísticos, que ofereçam um leque completo de atraçóes e serviços turístico-culturais, permitindo ocupar todo o ano, todo o território e o principal mercado-alvo, que cada vez mais procura experiências criativas e participativas.

É, neste contexto, que o património literário e a atividade turística a ele associada poderá ser um importante contributo para o desenvolvimento local económico, contribuindo para a construção de uma "marca" cultural e literária, identificativa e diferenciada em relação a outros destinos.

O património literário é um importante meio de preservação das singularidades e identidade local, que a diferencia dos restantes territórios, impedindo 
que o destino turístico entre na tendência crescente da homogeneização e globalização. Deste modo, o turismo literário torna-se capaz de promover "novos cenários" e captar novos públicos, configurando-se como uma alternativa (ou complemento, contribuindo para o prolongamento da estada) a outras formas de turismo e essencial na atração de fluxos turísticos durante a época baixa e para locais mais periféricos, essencialmente de menor densidade e procura.

\section{Património literário em Leiria}

\section{Rota dos escritores em Leiria}

A cidade de Leiria está localizada na regiáo Centro de Portugal, designadamente na sub-regiáo do Pinhal Litoral. A sua posição privilegiada, entre as principais áreas metropolitanas portuguesas - Lisboa e Porto -, decorre também de ser ponto de passagem/ligação através de algumas das vias de trânsito mais importantes em Portugal: IC2, A1, A8, A17 e EN109.

Entre as suas atividades socioeconómicas mais relevantes, o setor do turismo tem vindo a afirmar-se, não só devido à atraçáo principal do seu território, o Castelo de Leiria, como a novos produtos que complementam a oferta e atraem novos turistas.

Tal como referido, o património literário configura-se como um importante segmento do turismo cultural, o qual tem sido explorado pelo município de Leiria. De acordo com André (1995), a regiāo de Leiria sempre foi rica em "homens das letras", que nasceram, viveram ou passaram pela cidade. Atualmente, alguns são uma referência para a cultura leiriense e nacional, de tal maneira que fazem parte da Rota dos Escritores ${ }^{2}$ (Figura 2), iniciativa promovida pela

\footnotetext{
${ }^{2}$ No plano nacional, as iniciativas que promovem o conhecimento de obras literárias, de autores e de territórios a eles vinculados são recentes. A título de exemplo, podemos referir as atividades promovidas pela Fundação Eça de Queirós (a qual está presente também na Rota dos Escritores em Leiria, por via de uma parceria entre a Fundação e o Município de Leiria) e a iniciativa "Rota
} 
Câmara Municipal de Leiria (desde julho de 2012), com visitas guiadas em todos os segundos sábados de cada mês, que percorre vinte e oito pontos relacionados com a vida dos autores: ruas, casas onde nasceram ou viveram, praças, estátuas, avenidas e jardins relacionados com a sua vida ou obra.

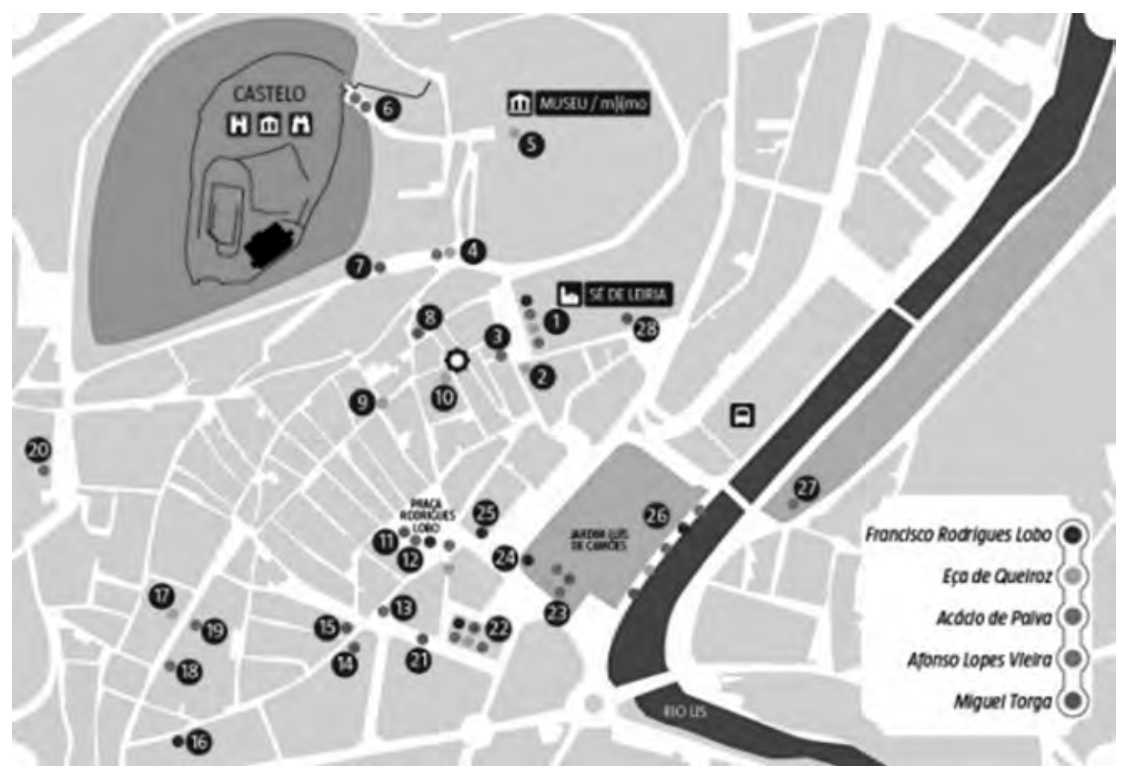

Figura 2

Rotas dos Escritores em Leiria

Fonte: www.cm-leiria.pt (07-04-2014).

Como nota Maurício (2013), o percurso tem uma duração de aproximadamente duas horas e pode ser realizado de modo formal ou informal - no primeiro caso, o município disponibiliza o apoio de dois guias especializados

dos Escritores do Século XX" (Afonso Lopes Vieira; Aquilino Ribeiro; Carlos de Oliveira; Eugénio de Andrade; Fernando Namora; Miguel Torga; Vergílio Ferreira), dinamizada pela Comissáo de Coordenação e Desenvolvimento Regional do Centro, cuja origem remonta ao ano de 2003. Carvalho (2009: 37) apresenta uma tipologia de itinerários literários em Portugal, com duas dezenas de exemplos, "divididos por categorias, conforme sejam publicados em livro, organizados por entidades públicas ou privadas, sejam enquadráveis no âmbito de projectos regionais ou se trate de sítios literários ou fundaçōes dedicadas a um escrito”. 
para orientar a visita e esclarecer eventuais dúvidas aos participantes. A informação sobre a Rota está disponível para consulta na página da internet da autarquia, bem como nos sites com os quais a Rota estabeleceu parcerias. Por outro lado, constata também a atenção que a rota tem recebido por parte dos meios de comunicação social, tanto regionais, como nacionais, e a sua consequente divulgação junto do grande público.

Os autores que fazem parte da Rota dos Escritores são Francisco Rodrigues Lobo, Eça de Queiroz, Acácio de Paiva, Afonso Lopes Vieira e Miguel Torga. Francisco Rodrigues Lobo nasceu em Leiria no século XVI e foi poeta e autor, apelidado de "cantor do Lis", considerado o primeiro grande poeta de Leiria; Acácio de Paiva nasceu em Leiria no século xix e foi poeta, prosador, crítico e jornalista, em cuja obra as imagens da cidade eram uma constante; Afonso Lopes Vieira também nasceu em Leiria no século XIX e dedicou-se à literatura e à ação cultural, fazendo parte do grupo da "Renascença Portuguesa", descreveu a regiāo e as povoaçóes circundantes, sendo, por isso, considerado um dos mais relevantes símbolos da literatura leiriense. Miguel Torga e Eça de Queiroz apenas passaram e viveram por Leiria, mas deixaram igualmente a sua marca. Miguel Torga teve um consultório médico, onde viveu até casar e foi descrito nas suas obras - aqui escreveu "Bichos"; Eça de Queiroz, figura incontestável da literatura portuguesa, teve uma maior influência na cidade, que justifica a importância dada pelo município, na construção de uma oferta turística literária distinta, que será analisada de seguida.

\section{Leiria Queiroziana: ligação de Eça à cidade e iniciativas culturais}

Eça de Queiroz nasceu em 1845 em Póvoa do Varzim e é a 30 de julho de 1870 que se desloca para Leiria, como administrador do concelho, após ter começado a exercer a sua atividade de advogado. Em Leiria, o escritor fica hospedado na Travessa da Tipografia n. ${ }^{\circ}$ 13, que é descrita na obra "O Crime do Padre Amaro" como a casa de Augusta Carminda (mãe de Amélia e primeira residência de Amaro), com outra localização - Rua da Misericórdia n. ${ }^{\circ} 9$. 
Eça de Queiroz permanece em Leiria um ano, até pedir a exoneração do seu cargo para se dedicar à carreira diplomática. Durante a sua estada na cidade, escreveu parte de "O Crime do Padre Amaro" e a sua parte de "O Mistério da Estrada de Sintra”, em colaboração com Ramalho Ortigão. "O Crime do Padre Amaro" é considerado o primeiro romance realista escrito em língua portuguesa e tem como cenário de grande parte da ação a cidade de Leiria. A narrativa está centrada no enredo da relação amorosa de um membro da igreja católica (o padre Amaro) com uma jovem beata (Amélia) - que é, de certa forma, aceite pelos clérigos do bispado.

A ação de "O Crime do Padre Amaro" refere lugares da cidade de Leiria possíveis de identificar, o que desencadeou a criação de uma rota com nome igual à obra, que passa pelos principais pontos do enredo (Figura 3): começa

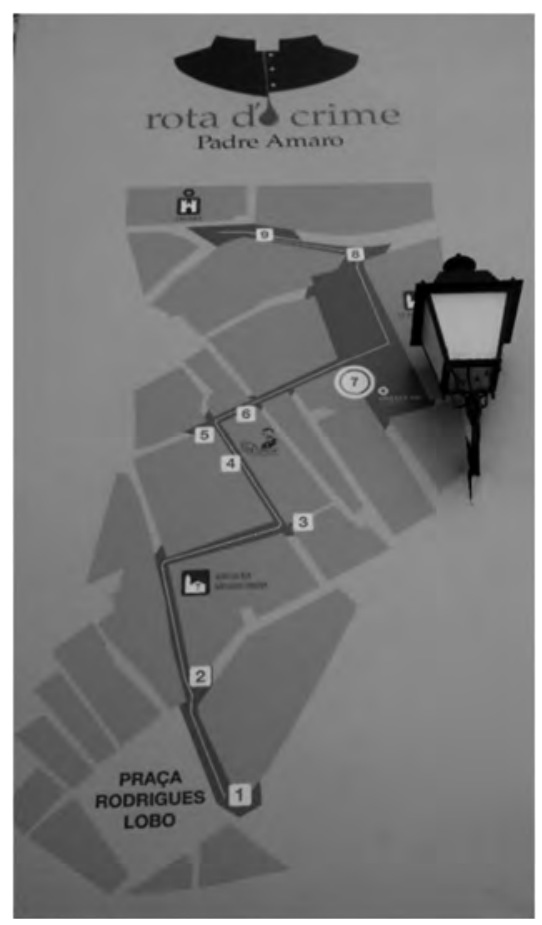

Figura 3

Rota d'O Crime do Padre Amaro

Fonte: Foto de Sara Fernandes, 06.04.2014. 
na Praça Rodrigues Lobo, que já em 1870 era local de encontro cultural no contexto da cidade, segue para a residência de Eça de Queiroz, assinalada por uma placa identificativa (Figura 4), e para o largo da Sé, onde decorre grande parte das cenas, e termina na Torre Sineira (Casa do Sineiro), local dos encontros entre Amaro e Amélia. Ao longo do percurso, o visitante é acompanhado pela interpretação da artista plástica Sílvia Patrício, com treze representações da obra em painéis de lona acompanhadas dos respetivos excertos, num total de $300 \mathrm{~m}^{2}$ preenchidos.

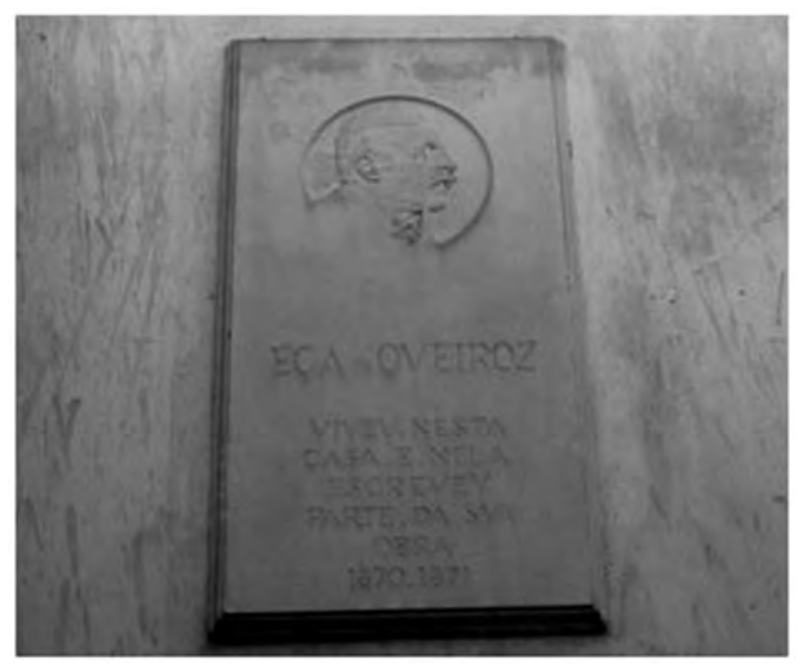

Figura 4

Placa de identificação da residência de Eça de Queiroz

Fonte: Foto de Sara Fernandes, 06.04.2014.

Apesar do seu estado de degradação, a casa onde morou Eça de Queiroz é identificada e junto a ela foi construído um edifício moderno que homenageia o escritor, a sua vida e obra, em colaboração com a Fundação Eça de Queiroz, e outras figuras literárias que passaram por Leiria - o Centro Cívico: Praça Eça de Queiroz (Figura 5). Este Centro é o ponto de partida da Rota dos Escritores (na 
Sala Eça de Queiroz) e desenvolve acçóes culturais e formativas para a difusão do património leiriense, da responsabilidade da associaçáo Sempreaudaz.

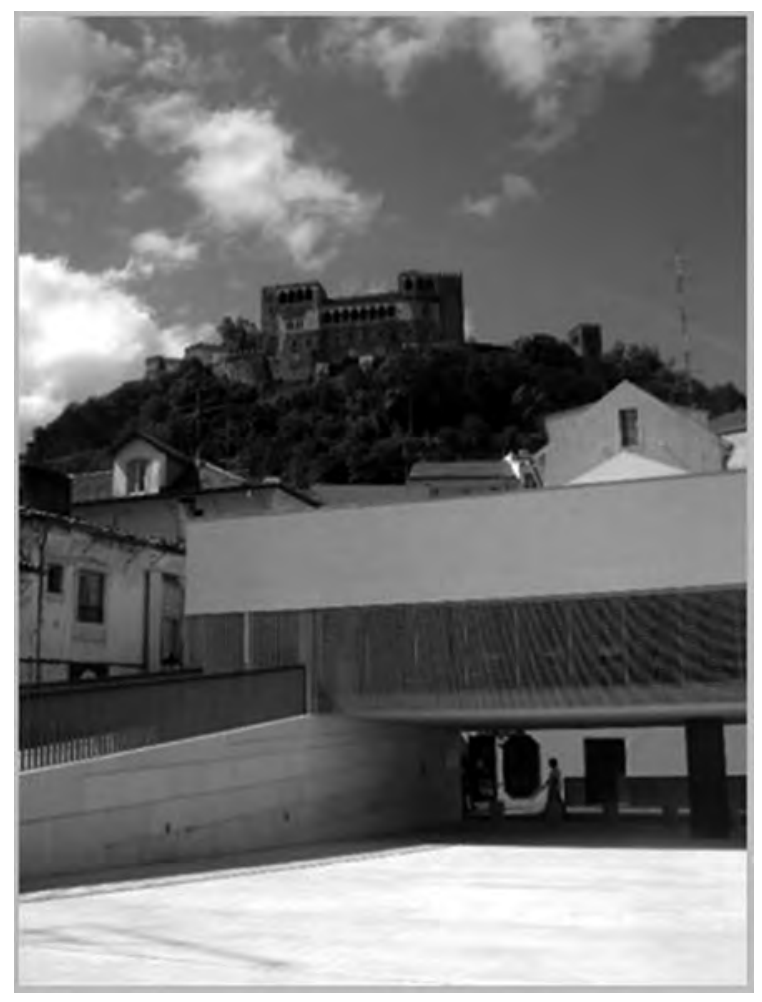

\section{Figura 5}

Centro Cívico, Praça Eça de Queiroz e Castelo de Leiria

Fonte: Foto de Sara Fernandes, 06.04.2014.

No caso da Torre Sineira da Sé de Leiria ${ }^{3}$, o estado de conservação não permitia ou dificultava bastante o acesso aos visitantes. Segundo Bernardes (2015), a intervenção na Torre Sineira da Sé (localizada na área mais alta da cidade,

3 Tem a particularidade de estar "afastada da sua igreja matriz" (Sé de Leiria, situada na baixa da cidade). Um vez que os sinos não "ecoavam com intensidade suficiente para alcançar as populaçôes mais afastadas" (Bernardes, 2015: 3), foi preciso escolher um ponto elevado para a construir (na área alta, próxima do castelo). É um elemento marcante da paisagem cultural de Leiria, com origem no século xviII. 
junto ao castelo) foi iniciada no final de 2014, no âmbito da Rota das Catedrais, e pretende valorizar este património da cidade e da diocese Leiria-Fátima, com a criaçáo de um "novo espaço museológico" e a possibilidade de o ligar (como complemento) à rota Queiroziana. "Após a abertura ao público, o espaço da torre e da casa será visitável sendo possível conhecer o carrilhão, o relógio, os pêndulos e o fosso da torre, além de aceder a informação histórica a propósito da muralha do Castelo de Leiria, e sobre a qual foi construída a Torre" (Bernardes, 2015: 8).

Por fim, consciente da riqueza patrimonial literária da cidade de Leiria e consequência do sucesso de visitas à Rota d'O Crime do Padre Amaro, confirmou-se o interesse da população pelo autor e, por isso, a Câmara Municipal desenvolveu um programa de atividades denominado "Eça 2014", que procura homenagear uma das principais figuras literárias nacionais, relacionando-a com a cidade e, deste modo, afirma Leiria como um "destino turístico literário e cultural" e a "cidade emblemática do Eça e do Crime do Padre Amaro", de acordo com as palavras do Vereador da Cultura, Gonçalo Lopes (in Região de Leiria, 31-01-2014).

Este programa assenta num conjunto de atividades alargado, a saber: Galeria Arte Urbana (com as representaçóes de Sílvia Patrício - Figura 6); seis visitas guiadas gratuitas da Rota d'O Crime do Padre Amaro, concluídas com concertos Queirosianos com o reportório da época da vida e obra do autor; doze espectáculos de teatro de rua pela Companhia de Teatro Leirena no centro histórico, que retrata a sua obra com humor e interatividade; as recriaçóes históricas "Leiria no Final do Século XIX" (Figura 7), entre 31 de maio e 1 de junho, com cerca de mil figurantes locais, e "Baile Queiroziano", que pretende recriar o ambiente da época de Eça em Leiria; Semana Gastronómica Queiroziana (março) com ementas retratadas pelo autor; visitas guiadas ao Centro Cívico para o público geral e para os alunos do ensino secundário; e encontros de personalidades no Centro Cívico para conversar acerca de Eça e temáticas associadas.

No presente, a literatura é considerada um processo de comunicação entre o autor e leitor em que, através dela, o autor transmite o seu ponto de vista e interpretação, tornando a literatura um instrumento de conservação da memória individual e coletiva de um lugar. 


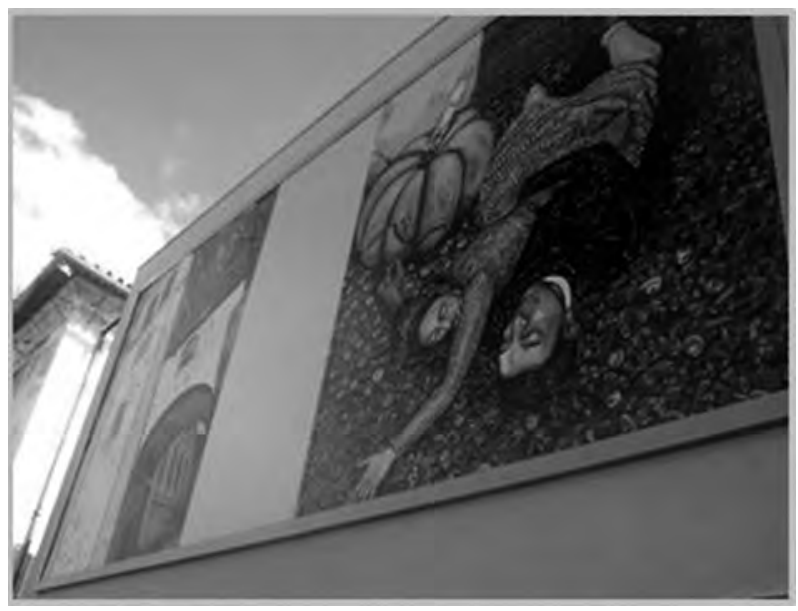

Figura 6

Painéis da Galeria Arte Urbana

Fonte: Foto de Sara Fernandes, 06.04.2014.

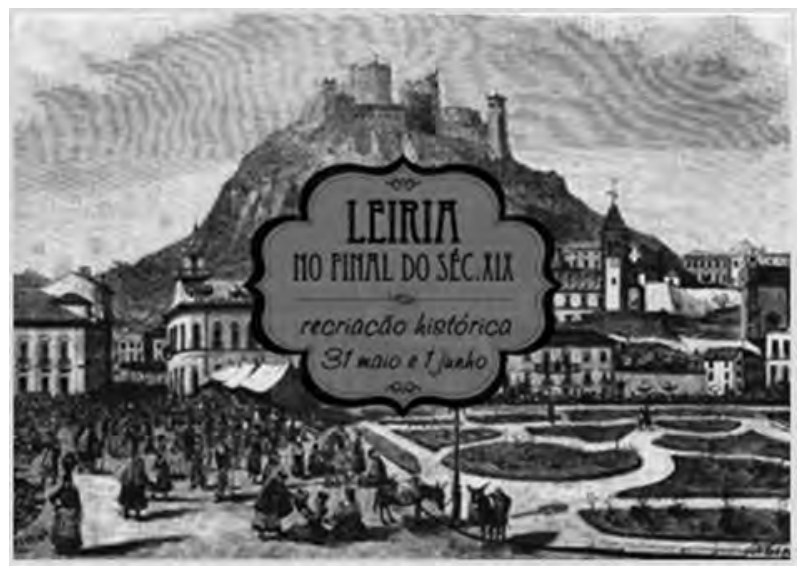

Figura 7

Cartaz da Recriação Histórica "Leiria no final do século xIX"

Fonte: Disponível em www.cm-leiria.pt (07.04.2014) 


\section{Consideraçóes finais}

O património literário assume-se, assim, como um elemento valorizador de um lugar, quando a ele associado um autor ou uma obra de referência, criando os sítios literários, isto é, locais associados a um autor ou obra, e os itinerários literários, que relacionam locais em rede com afinidades a um determinado autor.

Deste modo, o turismo literário afirma-se, cada vez mais, como um segmento do turismo cultural, dada a sua importância na preservação da "herança cultural" e a "conveniência geográfica" nos principais circuitos. De facto, o segmento "turismo e cultura" é uma prioridade futura, onde o património literário assume especial importância como marca cultural diferenciada, meio de preservação da identidade local e de captação de novos públicos, sobretudo em época baixa.

A cidade de Leiria, situada numa posição central entre as principais áreas metropolitanas nacionais, desde sempre teve uma larga tradição literária, o que motivou a criação da Rota dos Escritores, que homenageia Francisco Rodrigues Lobo, Eça de Queiroz, Acácio de Paiva, Afonso Lopes Vieira e Miguel Torga. No entanto, é Eça de Queiroz quem tem mais destaque, devido à sua importância no panorama nacional, com a construção do Centro Cívico em sua homenagem e o desenvolvimento da Rota d'O Crime do Padre Amaro, cuja parte da ação se desenrola na cidade. O sucesso destas iniciativas motivou a criação de um programa para o ano de 2014 - "EÇA 2014" -, que transporta o visitante para a época de Eça, através de várias atividades.

Em suma, destaca-se o papel positivo dos dirigentes leirienses, que procuram afirmar a cidade como um destino turístico cultural, para além do património histórico-arquitetónico, através do estudo e desenvolvimento de novos patrimónios, neste caso o literário, que deixou marcas na cidade. A passagem de Eça de Queiroz e "O Crime do Padre Amaro" são exemplos do papel do património literário na atratividade dos locais, sobretudo quando se trata de autores de referência. 


\section{Bibliografia e fontes}

Abreu, J. F. (2012). A Ilha da Madeira pela Mão dos Seus Poetas - Construção de um Roteiro Literário. Dissertaçáo de Mestrado, Universidade da Madeira. Recuperado em 5 de março, 2014 de http://hdl.handle.net/10400.13/503.

André, C. (1995). "Terra de Poetas. Leiria e a literatura de outrora" in II Colóquio sobre História de Leiria e a da sua Regiāo. Actas. Câmara Municipal de Leiria, pp. 17-38.

Bernardes, A. (2015). Torre Sineira da Sé de Leiria. Texto inédito elaborado no âmbito do Módulo I de Património Cultural (Mestrado em Lazer, Património e Desenvolvimento da Universidade de Coimbra).

Carvalho, I. (2009). Turismo Literário e Redes de Negócios: Passear em Sintra com Os Maias. Dissertação de Mestrado, Universidade de Aveiro. Recuperado em 5 de março, 2014 de http://hdl.handle. net/10773/1691.

Henriques, C. \& Quinteiro, S. (2011). "O Turismo Literário. Olhão sob a Perspectiva de João Lúcio" in International Conference on Tourism \& Management Studies, Algarve.

Herbert, D. (2001). "Literary Places, Tourism and The Heritage Experience" in Annals of Tourism Research, Vol. 28, N.o 2 (pp. 312-333).

Hoppen, A.; Brown, L. \& Fyall, A. (2014). "Literary tourism: Opportunities and challenges for the marketing and branding of destinations?" in Journal of Destination Marketing \& Management, n. ${ }^{\circ} 3$ (1) (pp. 37-47).

Maurício, M. (2013). Turismo Literário. Estudo de caso da Rota dos Escritores de Leiria. Texto inédito elaborado no âmbito do Módulo I de Património Cultural (Mestrado em Lazer, Património e Desenvolvimento da Universidade de Coimbra).

MEE (2013). Plano Estratégico Nacional de Turismo - Horizonte 2013-2015. Ministério da Economia e do Emprego. Recuperado em 16 de maio, 2013 de www.turismodeportugal.pt

Mendes, M. (2007). Na senda estética e poética dos itinerários turísticos e literários: o vale do Lima. Dissertaçáo de Mestrado, Universidade de Aveiro. Recuperado em 16 de maio, 2015 de http:// hdl.handle.net/10773/4793.

Richards, G. (2011). "Creativity and tourism: the state of the art" in Annals of Tourism Research, n. ${ }^{\circ} 38(4)$ (pp. 1225-1253).

Sardo, A. (2009). "Turismo Literário: A importância do património e dos sítios literários para o desenvolvimento turístico regional" in Simōes, J. M. e Ferreira, C. (Ed.), Turismos de Nicho: Motivaçôes, Produtos, Territórios (pp. 339-352). Lisboa: Centro de Estudos Geográficos da Universidade de Lisboa.

\section{Outros recursos}

Câmara Municipal de Leiria - www.cm-leiria.pt

"Centro Cívico abre em Setembro para homenagear Eça de Queiroz" in jornal Regiäo de Leiria, 12 de Agosto de 2012.

"Leiria propõe viagem ao passado a partir da memória de Eça de Queiroz" in jornal Regiáo de Leiria, 31 de janeiro de 2014. 